\title{
BUILDING A NATIONAL HERITAGE REGISTRY FOR THE SUDAN: THE FRIEDRICH W. HINKEL ARCHIVE DIGITIZATION PROJECT
}

\author{
S. Lawrenz \\ Deutsches Archäologisches Institut, Zentrale Berlin, Podbielski Allee 69-71, 14195 Berlin, Germany \\ solveig.lawrenz@dainst.de
}

KEY WORDS: Heritage Registry, Heritage Preservation, Digitization, Archival Material, Sudan

\begin{abstract}
:
The Republic of the Sudan is home to outstanding and diverse cultural heritage ranging from Neolithic sites of human activity and settlement to historic sites of the $19^{\text {th }}$ and $20^{\text {th }}$ century. While certain phases of the Sudan's cultural heritage such as the period of Egyptian influence during the second and first millennium B.C. have been the focus of archaeological research since the $19^{\text {th }}$ century, other aspects of the country's rich history have remained largely unknown locally and internationally due to a lack of documentation and registration of such sites. Since 2014, the German Archaeological Institute (DAI) has been engaged in an effort to support the creation of a national heritage registry in close cooperation with the National Corporation for Antiquities and Museums (NCAM) by digitizing the archive of German architect Friedrich W. Hinkel and engaging in capacity building measures focusing on analog and digital data curation. The archive contains structured information (photos, drawings, maps and assembled written documentation) regarding over 14,000 archaeological and historical sites in the Sudan using an alphanumeric coding system that allows for easy integration of data in a digital environment such as the DAI's IT infrastructure, the iDAI.world. As such the data assembled by Hinkel will serve as the basis of the national heritage registry currently in development.
\end{abstract}

\section{INTRODUCTION}

\subsection{Cultural Heritage in the Republic of the Sudan}

The cultural heritage of the Sudan dates back as much as 70,000 years to Lower Paleolithic sites in central Sudan (for an overview of the archaeology and history see Adams 1977; Wildung et al., 1997). Beginning in the late Paleolithic (ca. 40,000 to ca. 10,000 B.C.) period most archaeological sites are confined to the valley of the river Nile. Following the development of a fully sedentary lifestyle during the Neolithic in the $4^{\text {th }}$ millennium B.C. the first traces of Egyptian influences can be detected. Local Neolithic cultures such as the A- and C-groups of northern Sudan as well as the Kerma culture in the area of the Second to Third Cataract show evidence of trade with the Egyptian neighbors to the north. The early XII Dynasty marks the beginning of direct Egyptian influence in Lower Nubia with the construction of fortresses, temples and trading stations along the Nile, culminating in the conquest and establishment of colonies as far south as the Fourth cataract lasting well to the end of the XVIII Dynasty. The first millennium B.C. saw the development of a local Nubian empire in the Napatan region, the Kushite empire, creating a counterbalance to Egypt's continuing influence in the north. Borrowing certain cultural aspects such as architectural styles from its neighbors in the north, the archaeological remains of the Kushite empire (ca. 800 B.C. to 400 A.D.) consist of a large number of pyramids and temples in predominantly Egyptian styles adapted to local traditions and tastes. Following the decline of the Kushite empire the Christianization of Nubia in the $6^{\text {th }}$ century A.D. saw the rise of local Christian kingdoms later overtaken by Arab tribes in the $15^{\text {th }}$ century B.C. Since the early $19^{\text {th }}$ century the Sudan has been under the control of first Egyptian and later British forces, terminating the long-lasting influences of the Medieval age in the Sudan.

Archaeological activity in the Sudan since the late $19^{\text {th }}$ century has uncovered well over 14,000 sites in the Sudan, which since
1903 have been administered and protected by the Sudanese Antiquities Service (now the National Corporation for Antiquities and Museums), with corresponding legislation being passed after the Sudan's independence in 1952 and 1999. With every building older than 100 years becoming a possible heritage site and ongoing archaeological fieldwork conducted by Sudanese and international missions, the number of heritage sites is constantly increasing.

However, due to the political developments of the past 20 to 30 years the registration and documentation of archaeological and historic sites has suffered severe set-backs, resulting in a lack of information needed for the protection of said sites from destruction by construction and mining activities. The development of a national heritage registry is therefore of the utmost importance and interest, both for the National Corporation for Antiquities and Museums (NCAM) and for international researchers alike. The information held in the archive of Friedrich W. Hinkel, being the result of over 40 years of research in the Sudan since the early 1960 s, thus represents an important source of information concerning the cultural heritage in the Sudan.

\subsection{Friedrich W. Hinkel}

The architect Friedrich Wilhelm Hinkel was one of the most renowned researchers in the field of Sudanese archaeology and architecture, having spent more than 40 years living and working in the Sudan. The son of a merchant, Friedrich W. Hinkel was born on December 28, 1925 in Berlin, Germany. After World War II he returned to East-Berlin to become an apprentice bricklayer and carpenter, an experience that had a significant influence on his future as an architectural historian in the Sudan. From 1947 to 1950 he studied civil engineering and architecture at the Ingenieurschule in Magdeburg, after which he worked as an engineer, site manager and structural designer until joining the Freier Deutscher Gewerkschaftsbund (Free German Trade Union Federation) of the German Democratic Republic (GDR) in 1952. From here he transferred to the Deutsche Bauakademie (DBA) of 
the GDR, where he participated in the rebuilding of the Deutsche Staatsoper in Berlin (Berlin State Opera), a first foray into the reconstruction of architecture which later should become one of his main fields of activity and interest. It was when he began working as an Architect at the Akademie der Wissenschaften (Academy of Sciences) of the GDR in 1960 that he first traveled to the Sudan as part of the Humboldt University's expedition to Musawwarat es Sufra. He remained an official employee of the Academy until his retirement in 1990. In 1962, he was seconded by the Academy of Sciences to the Sudanese Antiquities Service to oversee the dismantling and transport of the temples at Aksha, Buhen, Semna West and Kumma (Semna East), as well as the rock-cut tomb from Debeira East and a large number of rock inscriptions to Khartoum in order to save them from their imminent destruction in connection with the construction of the Aswan Dam/High Dam. Without the assistance of trained professionals, technical equipment and only limited financial means he accomplished this task by relying on ancient construction techniques as well as his initial training as a bricklayer and carpenter by using simple tools and predominantly manual labor. The operation proved to be a success with all monuments arriving safely in Khartoum. In 1973, Hinkel was awarded the Medal of Merit, $1^{\text {st }}$ Class, of the Democratic Republic of the Sudan for his efforts to save these archaeological monuments from certain destruction through flooding.

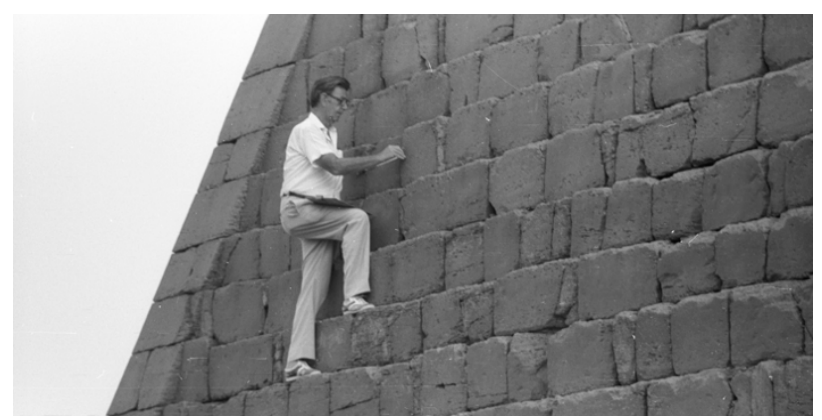

Figure 1. Friedrich W. Hinkel measuring blocks of pyramid N8 at Begrawiya/Meroe (Negative No. D-DAI-Z-Arch-FWH-F-

KB-sw-542-70, (C) Deutsches Archäologisches Institut).

From 1965 to 1973, he held the post of Architect of the Sudan Antiquities Service, giving finishing touches to the Sudan National Museum in Khartoum and designing the Ali Dinar Museum in El Fasher (Darfur) as well as restoring the architecture of the island-city of Suakin on the Red Sea Coast. It was in this phase of his work in the Sudan that Hinkel published the first three volumes of the Archaeological Map of the Sudan (Hinkel, 1977; Hinkel, 1979; Hinkel, 1992), a series of publications in which he planned to publish information on all archaeological and historic sites in the Sudan. In 1976, he became the main architect of the Directorate General of Antiquities and Museums of the Sudan, overseeing in the following years, among other things, a first round of restoration activities at the pyramids at Meroe (s. Fig. 1) as well as the excavation of the Temple of the Sun at Meroe, while also finishing his doctorate at the Academy of Sciences in 1980. From 1985 to 1988, he served as a consultant for the Antiquities Service.

After his official retirement in 1990 he dedicated most of his time to the publication of the results of his studies, publishing several supplement volumes to his publication series "The Archaeological Map of the Sudan" (Hinkel, 2001; Hinkel, 2002a; Hinkel, 2002b; Hinkel \& Ali Mohamed, 2002). In 1992 Hinkel received the Bundesverdienstkreuz (the Order of Merit of the Federal Republic of Germany) as one of the first East German researchers for his life's work. He was later honored with the Order of the Two Niles by the Republic of Sudan.

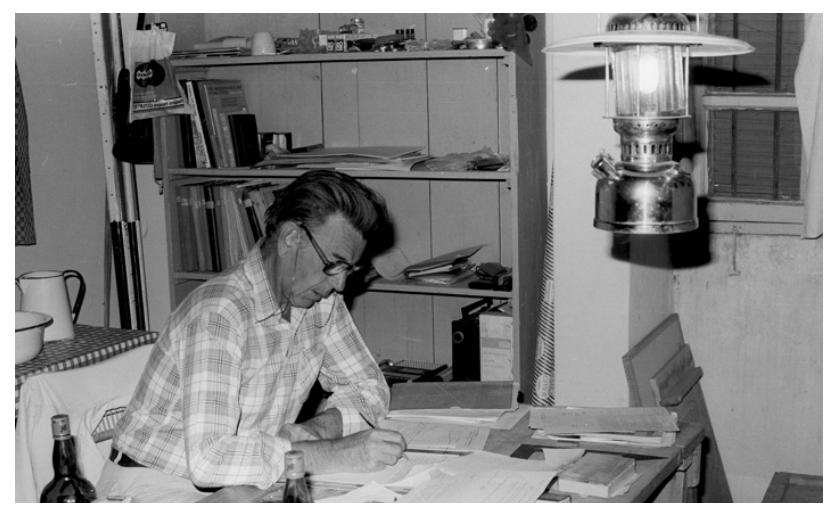

Figure 2. Friedrich W. Hinkel working in his rest house at Begrawiya/Meroe, 1983 (Negative No. D-DAI-Z-Arch-FWH-FKB-sw-389-55, (C) Deutsches Archäologisches Institut).

Following a short break in his fieldwork activities between 1989 and 1993, Hinkel resumed his work in the Sudan in 1994 as a member of the archaeological expedition of the Egyptian Museum Berlin to Naqa. By 1996 he had relaunched his effort to restore the pyramids at Meroe as part of a mission on behalf the Sudan Antiquities Service, a goal he pursued until his last season in the Sudan in 2004 partly with the support of private donors. After Friedrich W. Hinkel's death in 2007, his personal research archive was transferred to the Deutsches Archäologisches Institut (German Archaeological Institute) by his wife and daughter (for further information on Friedrich W. Hinkel see Yellin \& Adams, 2007; Schulte, 2007).

\section{THE DIGITIZATION OF ARCHIVE OF FRIEDRICH W. HINKEL}

\subsection{The Archive of Friedrich W. Hinkel}

The research estate of Friedrich Hinkel, which he had already referred to in several articles and books as a "Forschungsarchiv" (research archive), as well as his research library were ultimately set up at the DAI in 2013, going hand in hand with first efforts to identify the types of material and information the archive contains. The material assembled in the archive represents the results of over 40 years of work in the Sudan. It contains over 33.000 photographs, more than 12.000 slides (framed and unframed), 540 topographical maps, over 4.000 drawings in ink and pencil, more than 20.000 index cards as well as well over 400 folders containing geographically structured information on archaeological sites in differing stages of preparation for publication in his series "The Archaeological Map of the Sudan". What distinguishes Hinkel's archive from Sudan archives held at other archaeological research institutions is its underlying structuring principle using alphanumeric codes for site identification (see below) as well as the source and type of the information presented in various kinds of documentation. During the course of his life and work Hinkel sustained an intricate system of registering photographs and other material in personal inventories using and refining the already established system of registering sites and monuments and their respective documentation according to map sheets. This geographical structure also applies to the several hundred binders containing 
assorted written and other documentation, making it easy to navigate. Owing to his long-time work as an employee for the Sudanese Antiquities Service, Friedrich Hinkel had unprecedented access to both the archaeological sites in the Sudan and the relevant documentation of sites, monuments and Museums held at the Antiquities Service. For this reason, Hinkel's archive not only encompasses the documentation of his own work but also includes self-made copies (s. Fig. 2) of other important documentation pertaining to archaeological and historical sites in the Sudan Hinkel collected in preparation for his publication series. This includes a partly handwritten copy of the index card registry of the Sudan National Museum in Khartoum (Fig. 3) as well as transcripts of archival material pertaining to finds and sites discovered before the political independence of the Sudan in 1956. This documentation is of special importance for the ongoing work of NCAM and the international missions, since parts of this documentation have not survived in Khartoum, making the Hinkel archive the only repository of the information of said documents.

$$
\begin{aligned}
& \begin{array}{ccc}
\text { 45-0 MEROE } & \text { V } & G-7 \\
\text { NE-36-0/03-J-003110 } & & \text { Meratienteriod } \\
\hline
\end{array} \\
& \begin{array}{l}
\text { 22-12-4 From tomb W } 110 \text {. } \\
\text { fold heart annlet }
\end{array} \\
& \begin{array}{l}
\text { 22-12-4 From tomb W } 110 \text {. } \\
\text { fold heart annlet }
\end{array}
\end{aligned}
$$

$$
\begin{aligned}
& \text { Dr. Reusuer's exc. } 1923 \text { ((shouldread 1922)) } \\
& \text { [Dunham, D, 1963,225] }
\end{aligned}
$$

Figure 3. Example of an index card of the registry of the Sudan National Museum copied by Friedrich Hinkel with the addition of its alphanumeric site number.

\subsection{The alphanumeric structuring system of the Archaeological Map of the Sudan}

The alphanumeric codification (the so-called AMS-numbers) of archaeological sites used in Hinkel's publication series "The Archaeological Map of the Sudan" is largely based on the International Map of the World, founded in 1913. The International Map of the World consists of maps in the scale of 1:1,000,000, each of which hold an alphanumeric designation based on their location. Map sheets depicting areas in the northern hemisphere carry the identification $\mathrm{N}$ as well as a designation referring to their respective geographic latitude (a letter) and longitude (a two-digit number). The Sudan (including the Republic of South Sudan) is depicted in the map sheets ranging from NF-34 to NA-36.

Every 1:1,000,000 map sheet of the International Map of the World is divided into 16 maps in the scale of 1:250,000, named sheets A to $P$. This classification of the International Map of the World has been used for the registration of sites by the Sudan Antiquities Service since the early 20th century and was later refined by Friedrich Hinkel by adding three additional layers of geographic classification (Hinkel 1977, 24-26). The map sheets with a scale of 1:250,000 were thus divided by Hinkel into 24 rectangles representing a longitude of 15 ' numbered 1 to 24 . Each of these rectangles was then divided into 25 units named A to Y representing a longitude of 3 '. Each site (or sometimes an architectural structure such as a pyramid or temple) is assigned an individual AMS-Number based on its location as well as a unique identifier. The Hafir at Awlib for instance (an artificial ancient water basin) was assigned the AMS-number NE-36-O/3O-3 by Hinkel locating it north of the Wadi el Hwad, east of the town of Kabushiya. The final identifier " 3 " suggests that this was the third site in this particular 3' rectangle Hinkel assigned a name to.

Due to the detail of the system and the resulting AMS-numbers it is possible to locate archaeological sites in the Sudan within an area of 5,18 by $5,54 \mathrm{~km}$ using only its alphanumeric designation as a reference.

An analysis of AMS-numbers mentioned in Hinkel's publications and the archival material held at the DAI yielded over 14,000 AMS-numbers for archaeological and historical sites in the Sudan. Due to differing sources of the information used by Hinkel to attribute AMS-numbers not all registered sites are associated with detailed geographic data such as precise coordinates. The use of the alphanumeric numbering system employed by Hinkel, however, makes it possible to locate each site within the borders of its last associated rectangle or map sheet, allowing for the registration of sites based on historic data and oral tradition.

The historical and archaeological sites defined by Hinkel using his AMS-system were integrated into the iDAI.gazetteer in the process of the digitization project.

\subsection{The Digital Hinkel Archive in the iDAI.world}

With the generous support of the Qatar Sudan Archaeological Project (09/2014 until 03/2016) and the German Foreign Ministry (beginning in 04/2016) it was possible to digitize large parts of Friedrich W. Hinkel's research archive. The digitization was done in cooperation with the CoDArchLab at the University of Cologne and the National Corporation for Antiquities \& Museums in Khartoum. The digitization of Hinkel's archive also served as a pilot project for the digitization of the DAI's archives, some of which can be traced back to the foundation of the institute in 1829.

The process of digitization included the archival registration of every digitized item under the supervision of an archive specialist as well as other preparatory steps such as the paging of all paper documents. The digitization itself was conducted by service providers specialized in the field of the digitization of archival material with the exception of the digitization of the large scale topographic maps and the drawings, which required specialized equipment to avoid distortions.

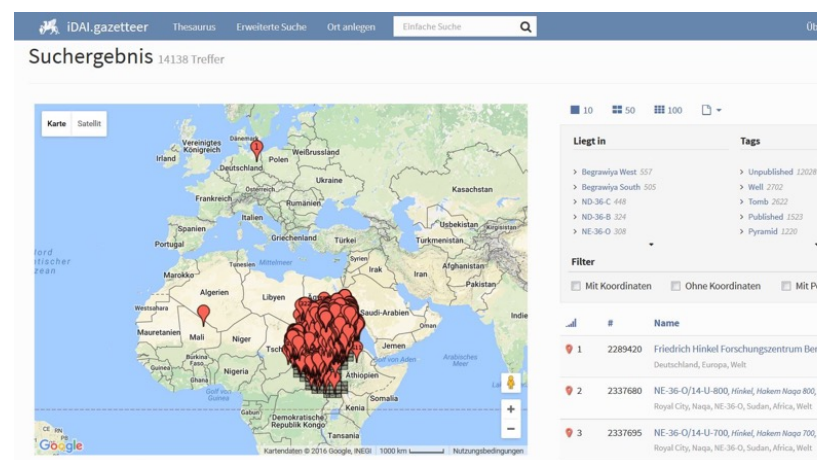

Figure 4. Screenshot of the iDAI.gazetteer showing the pointcloud for the archaeological and historical sites in the Sudan. 
The digitized items were then integrated into two applications of the web-based iDAI.world: iDAI.objects and the iDAI.bookbrowser. The data incorporated into iDAI.objects consists of all individual digitized items (photographs, slides, drawings and topographic maps) which can be associated with one single site or place registered in the iDAI.gazetteer. This way, the information for each site is connected through its unique alphanumeric code, making search queries regarding specific sites easy and efficient. Digitized items consisting of several pages or with and overarching theme or content were integrated into the iDAI.bookbrowser to maintain the integrity of the archival material in form and content. The descriptive metadata added for each digitized item in iDAI.objects or compilation in the iDAI.bookbrowser in German and English is based on Hinkel's own assessment of the material as recorded in his personal inventories. Thus, each dataset represents the state of Hinkel's research while being tied together by a systematic geographic structure. The results of the digitization project are available online (https://arachne.dainst.org/project/hinkel) and can be accessed following registration with the staff of the archive (hinkel-archiv@dainst.de).

\section{CREATING A NATIONAL HERITAGE REGISTRY FOR THE SUDAN}

Starting with the digitization of the archive of Friedrich Hinkel in the summer of 2014 the DAI has been engaging in an ongoing discussion with NCAM on how the research and information collected by Hinkel could best be put to use to protect and analyze the Sudan's cultural heritage. It soon became clear that the underlying geographical structure of the data using an already established system at NCAM and the type of information contained within the Hinkel-Archive makes it particularly suited as the basis for a national heritage registry for the Sudan. Since 2015 regular meetings have been held both in Berlin and Khartoum aimed at developing a data model for a digital heritage registry encompassing all possible requirements set by the Antiquities Service for the successful management of the Sudan's cultural heritage. Issues that need to be addressed in such a registry include both administrative and research aspects. On the administrative side information regarding ongoing and past field work, conservation effort, objects associated with the site and other site management issues such as information regarding the legal status of the site are of great importance for the day-to-day work of the Antiquities Service. In addition, research related information such as past and present photographs, drawings, reports and other compilations of the results of the respective missions will complete the information assembled for each site. In order to collate the relevant data for a national registry and to assess the technical requirements needed to incorporate research data all missions have been asked to submit samples of their raw data files in accordance with the Antiquities Ordinance of 1999. The development of the data model and database for the heritage registry is scheduled for 2018 with the implementation on a local server-network planned for the same year.

Apart from the development of the digital heritage registry the DAI also supports NCAM with a number of capacity building efforts aimed at establishing an analog archive in order to aid the preservation and conservation of essential documentation at NCAM.

\section{REFERENCES}

Adams, W. Y., 1977. Outline History of Nubia and the Sudan. In: The Archaeological Map of the Sudan. A Guide to its Use and Explanation of its Principles, Akademie Verlag Berlin, Berlin, pp. 3-12.

Hinkel, F. W., 1977. The Archaeological Map of the Sudan. A Guide to its Use and Explanation of its Principles, Akademie Verlag Berlin, Berlin.

Hinkel, F. W., 1979. The Archaeological Map of the Sudan II. The Area of the South Libyan Desert, Akademie Verlag Berlin, Berlin.

Hinkel, F. W., 1992. The Archaeological Map of the Sudan VI. The Area of the Red Sea Coast and Northern Ethiopian Frontier, Akademie Verlag Berlin, Berlin.

Hinkel, F. W., 2001. The Archaeological Map of the Sudan, Supplement 1, Der Tempelkomplex Meroe 250, Monumenta Sudanica, Berlin.

Hinkel, F. W., 2002a. The Archaeological Map of the Sudan, Supplement 4, Die Royal City von Meroe und die repräsentative Profanarchitektur, Monumenta Sudanica, Berlin.

Hinkel, F. W., 2002b. The Archaeological Map of the Sudan, Supplement 5, Zwei baltendeutsche Reisende in Ägypten und Nubien, 1815 und 1823, Monumenta Sudanica, Berlin.

Hinkel, F. W. \& Ali Mohamed, A., 2002. The Archaeological Map of the Sudan, Supplement 3, Catalogue of Objects in the Sudan National Museum, Nos. 00001-04000, Monumenta Sudanica, Berlin.

Schulte, A. J., 2007. Friedrich Hinkel (Geb.1925), http://www.tagesspiegel.de/berlin/friedrich-hinkel-geb1925/1034750.html (12 Jun. 2017).

Wildung, D. et al., 1997. Sudan. Ancient Kingdoms of the Nile, Flammarion, Paris - New York.

Yellin, J. \& Adams, W. Y., 2007. Friedrich Wilhelm Hinkel (1925 - 2007), Sudan \& Nubia, 11, pp. 127-128. 